\title{
Photothermal Spectroscopic Characterization in CdSe/ZnS and CdSe/CdS Quantum Dots: A Review and New Applications
}

\author{
Viviane Pillaㄹ, Egberto Munin², Noelio O. Dantas'1, \\ Anielle C. A. Silva ${ }^{1}$ and Acácio A. Andrade ${ }^{1}$ \\ ${ }^{1}$ Federal University of Uberlândia-UFU, Uberlândia, MG \\ ${ }^{2}$ University Camilo Castelo Branco- UNICASTELO, São José dos Campos, SP \\ Brazil
}

\section{Introduction}

Nanostructured semiconductors or Quantum Dots (QDs) are materials in continuous development that hold potential for a variety of new applications, including uses in fluorescent labels for biomedical science, photonic devices and sensor materials (Bruchez et al., 1998; Prasad, 2004; Sounderya \& Zhang, 2008). In biomedical applications, several nanodiagnostic assays have been developed that use QDs. They have been applied to diagnostics, the treatment of diseases, bioimaging, drug delivery, engineered tissues and biomarkers (Sounderya \& Zhang, 2008). For example, CdSe/ZnS dendron nanocrystals have been used as biosensor systems for detection of pathogens such as Escherichia Coli and Hepatitis B (Liu, 2007). CdSe/ZnS core-shell nanocrystals have been shown to be useful for tailoring the fluorescence of dental resin composites (Alves et al., 2010). Core-shell quantum dots (CS) have been used as heteronanocrystals, structures that allow optical amplification because of their stimulated emission of single-exciton states (Klimov et al., 2007), and highquality CdSe/ZnS doped titania and zirconia optical waveguides have been prepared (Jasieniak et al., 2007).

CdSe/ZnS and CdSe/CdS core-shell semiconductor nanocrystallites are II-VI semiconductor systems and Type I QDs; i.e., both electrons and holes are confined to the core of the core-shell QDs (Jasieniak et al., 2007; Kim et al., 2003). A CdSe nanocrystal core with band gap of (1.7-1.76) eV (Kortan et al., 1990; Lee et al., 2006) is often covered by another semiconductor shell with a high-energy band gap, such as ZnS or CdS, to improve the radiative quantum efficiency by passivating the nonradiative recombination sites at the surface (Dabbousi et al., 1997; Kortan et al., 1990). ZnS and CdS present band gap of (3.8-4.1) eV (Lippens \& Lannoo, 1989; Rathore et al., 2008) and (2.5-3.9) eV (Banerjee et al., 2000; Martínez-Castañón et al., 2010), respectively. In such core-shell nanocrystals, the shell provides a physical barrier between the optically active core and the surrounding medium, making the nanocrystals less sensitive to environmental changes, surface chemistry, and photo-oxidation. Therefore the shell provides an efficient passivation of the surface trap states, giving rise to a strongly enhanced fluorescence quantum yield. 
Recently, a new class of CdSe QDs called magic-sized nanocrystals (MSNs), with sizes from 1 to $2 \mathrm{~nm}$ and well-defined structures, has attracted considerable attention because of its novel physical properties. The most notable of these new properties are: a high stability during and after growth (Dagtepe et al., 2007), closed-shell structures (Chen et al., 2005), the presence of few unit cells, demonstrating strong quantum confinement similar to atoms (Soloviev et al., 2000), and different thermodynamically stable structures (Jose et al., 2006a; Nguyen et al., 2010). Moreover, these MSNs exhibit a high surface to volume ratio, which means that most of the atoms are located at the surface. For this reason, the passivating ligands contribute a significant portion of the total number of the atoms of the MSN, so that the dispersing medium can dramatically affect their properties (McBride et al., 2010). Therefore, the synthesis of stable nanocrystals via colloidal aqueous solutions is extremely important because it prevents changes in dispersion media, thereby preserving the surface properties of the MSNs. This approach yields a physiologically compatible medium that is useful in medical and biotechnological applications.

The ideal QDs for use in nanobiotechnology trials should be thermodynamically stable and have homogeneous dispersion, high radiative quantum efficiency, a very broad absorption spectrum, low levels of nonspecific links to biological compounds and, most importantly, stability in aqueous media. Obtaining all these characteristics simultaneously has been extremely difficult. Therefore, the fabrication of nanocrystals directly in an aqueous phase is of great interest because it would be highly reproducible, inexpensive, minimally toxic and capable of forming products that are easily dissolved in water. Close control of the optical and structural properties of MSNs (for example, CdSe) that are synthesized directly in a colloidal aqueous solution is possible because these properties are strongly affected by various parameters of the synthesis process, such as the Cd/Se molar ratio (Qu \& Peng, 2002), the cadmium precursor type (Peng \& Peng, 2002), the precursor concentration (Ouyang et al., 2008), reflux time (Jose et al., 2006b), the stabilizer type (Kilina et al., 2009; Park et al., 2010), and the reaction medium (Baker \& Kamat, 2010; Dagtepe \& Chikan, 2010; $\mathrm{Yu}$ et al., 2010). Furthermore, QD biomarkers have several advantages over organic dyes, such as high molar absorption, a broad absorption spectrum, a narrow emission spectrum and high photostability (Resch-Genger et al., 2008).

The solvent used to suspend the solute samples can exert important influence on such properties as the radiative quantum efficiency, absorption and emission spectra, stabilization and thermal parameters (including thermal diffusivity, thermal conductivity and the thermal coefficient of the refractive index) (Pilla et al., 2007; Lo et al., 2009) of the investigated materials. In this way, for a nanoparticle to be a candidate for practical applications, it is important to characterize their thermo-optical properties. The present work reports the thermo-optical properties of cadmium selenide/zinc sulfide (CdSe/ZnS) core-shell colloidal solutions measured with two techniques: the well-known Thermal Lens (TL) technique (Baesso et al., 1994; Shen et al., 1992; Snook \& Lowe, 1995) and analysis of the laser-excited ring patterns caused by thermally induced self-phase modulation (SPM) effects, an alternative method that is referred to in this work as the thermal spatial self-phase modulation (TSPM) technique (Dabby et al., 1970; Du \& Liu, 1993; Durbin et al., 1981; Hickmann et al., 1992; Khitrova et al., 1993; Ono \& Kawatsuki, 1997; Ono \& Saito, 1999; Torruellas et al., 1995; Valley et al., 1990; Whinnery et al., 1967; Yang et al., 2005). TSPM may be described by Kirchhoff's diffraction integral (KDI) applied to the propagation of a laser 
beam in a nonlinear medium (Catunda \& Cury, 1990; Pilla et al., 2003). The theoretical calculation predicted by KDI corroborates the TSPM experimental results (Pilla et al., 2009). Thermo-optical characterization was performed on samples of CdSe/ZnS core-shell QDs incorporated into Poly(methyl methacrylate) (PMMA) suspended in tetrahydrofuran (THF), toluene or chloroform solvent and CdSe/ZnS core-shell QDs suspended in toluene or an aqueous colloidal solution. The thermo-optical properties, such as the refractive index temperature coefficient $(d n / d T)$, fraction thermal load $(\varphi)$ and radiative quantum efficiency $(\eta)$ of the QD samples were determined. For CdSe/ZnS core-shell QDs suspended in toluene, the characterization was performed as a function of core size $(\sim 2-4 \mathrm{~nm})$. The present study reports on the process of synthesis as well as the morphologic and $\eta$ results of coreshell CdSe/CdS MSNs as a new study. The results obtained via Raman, absorbance and fluorescence spectroscopy, as well as the measurement of the morphology by atomic force microscopy, strongly confirm the formation of core-shell CdSe/CdS MSNs via aqueous colloidal solution.

\section{Theoretical basis for photothermal spectroscopic characterization}

\subsection{Thermal Lens (TL) technique}

In TL experiments (Baesso et al., 1994; Lima et al., 2000; Shen et al., 1992; Snook \& Lowe, 1995) in a two-beam (pump and probe) configuration, the heat source profile, $Q(r)$, is proportional to the Gaussian intensity profile of the excitation beam, which is expressed as $\mathrm{I}_{\mathrm{e}}(\mathrm{r})=\left(2 \mathrm{P}_{\mathrm{e}} / \pi \mathrm{w}_{\mathrm{e}}^{2}\right) \exp \left(-2 \mathrm{r}^{2} / \mathrm{w}_{\mathrm{e}}^{2}\right)$, where $\mathrm{P}_{\mathrm{e}}$ is the power of the excitation beam with radius $\mathrm{w}_{\mathrm{e}}$ at the sample. The temporal evolution of the temperature profile, $\Delta \mathrm{T}(\mathrm{r}, \mathrm{t})$, of the sample can be obtained by the heat conduction equation. In experiments with short excitation pulses, heat diffusion can be neglected and $\Delta \mathrm{T}(\mathrm{r}, \mathrm{t})$ is proportional to the Gaussian intensity profile of the excitation beam, $\mathrm{I}_{\mathrm{e}}(\mathrm{r})$. For long pulse or continuous waves $(\mathrm{cw})$ experiments, however, the effect of heat diffusion is important, and, consequently, $\Delta T(r, t)$ is wider than $\mathrm{I}_{\mathrm{e}}(\mathrm{r})$. For $\mathrm{t}$ $>>\tau_{c}$ (where $\tau_{c}$ is the characteristic heat diffusion time), the on-axis temperature rise is proportional to the absorbed excitation power $\left(\mathrm{P}_{\mathrm{e}, \mathrm{abs}}\right)$ and inversely proportional to the thermal conductivity $\mathrm{K}\left(\Delta \mathrm{T}(0, \mathrm{t}) \propto \mathrm{P}_{\mathrm{e}, \mathrm{abs}} / \mathrm{K}\right)$, but it does not depend on $\mathrm{w}_{\mathrm{e}}$.

The TL effect is created when the excitation laser beam passes through a sample of thickness L, and the absorbed energy is converted into heat. Heating changes the refractive index of the material and causes a thermally-induced phase change, $\Delta \phi_{\mathrm{TH}}$, expressed as (Shen et al., 1992):

$$
\begin{gathered}
\Delta \phi_{T H}=\frac{\theta}{\tau_{c}} \int_{0}^{t} \frac{1}{1+2 t^{\prime} / \tau_{c}}\left[1-\exp \left(-\frac{2 r_{2}^{2} / \mathrm{w}_{e}^{2}}{1+2 t^{\prime} / \tau_{c}}\right)\right] d t^{\prime}, \\
\theta=-\varphi\left(\frac{\mathrm{P}_{\mathrm{e}, \mathrm{abs}}}{K \lambda_{p}} \frac{d n}{d T}\right),
\end{gathered}
$$

where $\mathrm{P}_{\mathrm{e}, \mathrm{abs}}=\mathrm{P}_{\mathrm{e}} \alpha \mathrm{L}_{\text {eff }}, \alpha\left(\mathrm{cm}^{-1}\right)$ is the optical absorption coefficient at the excitation wavelength $\left(\lambda_{\mathrm{e}}\right), \mathrm{L}_{\mathrm{eff}}=\left(1-\mathrm{e}^{-\alpha} \mathrm{L}\right) / \alpha$ is the effective length, $\mathrm{L}(\mathrm{cm})$ is the sample thickness, $\lambda_{\mathrm{p}}$ is the wavelength of the probe beam, $\mathrm{dn} / \mathrm{dT}$ is the refractive index temperature coefficient, 
and $\varphi$ is the absolute nonradiative quantum efficiency, which represents the fraction of the absorbed energy converted into heat. $\tau_{\mathrm{c}}=\mathrm{w}_{\mathrm{e}} 2 / 4 \mathrm{D}$, where $\mathrm{w}_{e}$ is the excitation beam radius at the sample, $D=K / \rho C$ is the thermal diffusivity $\left(\mathrm{cm}^{2} / \mathrm{s}\right), K$ is the thermal conductivity $(\mathrm{W} / \mathrm{cmK}), \rho$ is the density $\left(\mathrm{g} / \mathrm{cm}^{3}\right)$, and $\mathrm{C}$ is the specific heat $(\mathrm{J} / \mathrm{gK})$.

The electric field of the probe beam as it leaves the sample can be expressed as $\varepsilon_{S}\left(\rho_{1}\right)=\varepsilon\left(\rho_{1}\right) \times \exp \left(-\mathrm{i} \Delta \phi_{\mathrm{NL}}\right)$, where $\Delta \phi_{\mathrm{NL}}$ is the phase change caused by the nonlinearity of the sample (which may include Kerr and thermal components), $\varepsilon\left(\rho_{1}\right)$ is the field of the probe beam at the entrance face of the sample, $\rho_{1}=\left[\left(\mathrm{x}_{1}{ }^{2+} \mathrm{y}_{1}{ }^{2}\right) / \mathrm{w}_{1}{ }^{2}\right]^{1 / 2}$, and $\mathrm{w}_{1}$ is the beam waist. In this case, $\Delta \phi_{\mathrm{NL}}$ is approximately equal to $\Delta \phi_{\mathrm{TH}}$ and is expressed by Eq. 1 (a-b). The field $\varepsilon\left(\mathrm{r}_{2}\right)$ at a point $\left(\mathrm{x}_{2}, \mathrm{y}_{2}, \mathrm{z}+\mathrm{d}\right)$ in the observation plane $\mathrm{P}$, located at a distance $\mathrm{d}$ away from the sample (S plane), is given by the sum of the optical fields caused by all points in the $S$ plane and is given by the following expression (Pilla et al., 2003):

$$
\varepsilon\left(r_{2}\right)=\frac{i 2 \pi}{\lambda_{p} d} \exp \left[-\frac{i 2 \pi}{\lambda_{p}}\left(d+\frac{r_{2}^{2}}{2 d}\right)\right] \int_{0}^{\infty} \exp \left(-\frac{i \pi r_{1}^{2}}{\lambda_{p} d}\right) \varepsilon_{s}\left(r_{1}\right) J_{0}\left(\frac{2 \pi r_{1} r_{2}}{\lambda_{p} d}\right) r_{1} d r_{1}
$$

where $r_{i}^{2}=x_{i}^{2+} y_{i}^{2}(i=1$ or 2$)$ and $J_{0}\left(2 \pi r_{1} r_{2} / \lambda_{p} d\right)$ is the zero-order Bessel function. The variation of the probe beam on-axis intensity, $\mathrm{I}(\mathrm{t}) \approx\left|\varepsilon\left(\mathrm{r}_{2}=0\right)\right|^{2}$, can be calculated using Eq. (2) at $r_{2}=0$ (central part of the probe laser beam) in the $c w$ excitation regime (Lima et al., 2000; Shen et al., 1992; Snook \& Lowe, 1995):

$$
I(t)=I(0)\left[1-\frac{\theta}{2} \tan ^{-1}\left(\frac{2 m V}{\left[(1+2 m)^{2}+V^{2}\right] \tau_{c} / 2 t+1+2 m+V^{2}}\right)\right]^{2},
$$

where $\mathrm{I}(0)$ is the on-axis intensity when $t$ is zero; $\mathrm{m}=\left(\mathrm{w}_{1} / \mathrm{w}_{\mathrm{e}}\right)^{2}, \mathrm{~V}=\mathrm{z}_{1} / \mathrm{z}_{\mathrm{op}}, \mathrm{z}_{1}$ is the distance between the sample and probe beam waist, $z_{\mathrm{op}}=\pi \mathrm{w}_{\mathrm{op}}{ }^{2} / \lambda_{\mathrm{p}}$ is the probe beam Rayleigh range, $z_{\text {op }}<<z_{2}$ (where $z_{2}(\mathrm{~cm})$ is the distance between the sample and TL detector) and $w_{\text {op }}$ is probe beam radius at the focus with wavelength $\lambda_{\mathrm{p}}$.

The thermally induced distortion of the laser beam as it passes through the sample is described by the optical path-length $(\mathrm{S})$ change $\left(\mathrm{ds} / \mathrm{dT}=\mathrm{L}^{-1} \mathrm{dS} / \mathrm{dT}\right)$, which results in lensing at the sample. The propagation of a probe laser beam through the TL will result in either spreading $(\mathrm{ds} / \mathrm{dT}<0)$ or focusing $(\mathrm{ds} / \mathrm{dT}>0)$ of the beam, depending mainly on the temperature coefficients of the electronic polarizability of the sample, stress and thermal expansion (in the case of liquid samples, $d s / d T \approx d n / d T$ ).

In the dual beam mode-mismatched configuration with excitation and probe beams, the normalized transient signal amplitude is approximately the phase difference $(\theta)$ of the probe beam between $r=0$ and $r=\sqrt{2} \mathrm{w}_{e}$ induced by the pump beam, given by Eq. (1b). The normalized parameter, $\Theta=-\theta / \mathrm{P}_{\mathrm{e}} \alpha \mathrm{L}_{\mathrm{eff}}$, for liquid samples is defined as (Lima et al., 2000):

$$
\Theta=\varphi\left(\frac{1}{K \lambda_{p}} \frac{d n}{d T}\right)
$$


and

$$
\varphi=1-\eta \frac{\lambda_{e}}{\left\langle\lambda_{e m}\right\rangle}
$$

where $\left\langle\lambda_{\mathrm{em}}\right\rangle$ is the average emission wavelength and $\eta$ is the fluorescence quantum efficiency or quantum yield.

Sheldon et al. determined the optimization of the TL technique for samples located at position $\mathrm{Z}_{1}=1.7 \mathrm{z}_{\mathrm{op}}$ (Sheldon et al., 1982). However, Fang and Swofford noted that the TL technique becomes more sensitive when using a system with two beams, a probe and a pump, with waists that do not coincide (Fang \& Swofford, 1979). Berthoud et al. derived a theoretical model for an arrangement with two beams in the mode-mismatched configuration (Berthoud et al., 1985). The results of these studies showed that the increased sensitivity of the technique is a result of placing the sample in the focus of the excitation beam $\left(\mathrm{w}_{\mathrm{e}}=\mathrm{w}_{\mathrm{oe}}\right)$ and outside the focus of the probe beam. A quantitative model was developed (Shen et al., 1992) for this technique in mode-mismatched configuration so that it could be used for steady-state and time-resolved measurements, in both the single-beam and dual beam configurations.

\subsection{Self-induced phase modulation technique}

Thermally induced self-phase-modulation (SPM) effects can be understood as the ability of the excitation beam to induce spatial variations of the refractive index, leading to a phase shift that depends on the transverse distance from the beam axis. The transverse self-phase modulation (Dabby et al., 1970; Du \& Liu, 1993; Durbin et al., 1981; Hickmann et al., 1992; Khitrova et al., 1993; Ono \& Kawatsuki, 1997; Ono \& Saito, 1999; Petrov et al., 1994; Torruellas et al., 1995; Valley et al., 1990; Whinnery et al., 1967; Yang et al., 2005) is also implicate in the emergence of rings in the pattern of transmitted light when $\Delta \phi_{\mathrm{NL}}>>2 \pi$. The number of rings $N \approx \Delta \phi_{\mathrm{NL}} / 2 \pi$ (Durbin et al., 1981; Ono \& Saito, 1999), in the case where $\Delta \phi_{\mathrm{NL}}$ $=\Delta \phi_{\mathrm{TH}}($ Eq. $1 \mathrm{a}-\mathrm{b})$ can be determined as a function of $\mathrm{P}_{\mathrm{e}}$ by using the following expression (Andrade et al., 1998; Catunda et al., 1997; Pilla et al., 2009):

$$
N=1.3 \frac{\varphi \alpha L_{e f f}}{2 \pi K \lambda_{p}} \frac{d n}{d T} P_{e}
$$

Mathematically, the equation that describes the deflection path $(\beta)$ of a beam that spreads in two components $\left(r_{1}\right.$ and $r_{2}$ ) because of a change in the refraction index $\Delta n(r)$ caused by the laser beam at a distance $r$ from its propagation axis, is defined as follows (Dabby et al., 1970):

$$
\beta(r)=\left|\frac{\partial}{\partial r} \int_{0}^{\mathrm{L}} \frac{\Delta \mathrm{n}(\mathrm{r}, \mathrm{z}) \mathrm{dz}}{\mathrm{n}_{0}}\right|
$$

where $\mathrm{n}_{0}$ is the intensity-independent part of the refractive index. The interference rays that constitute the laser beam emerge parallel with different phases after crossing the nonlinear medium, i.e., $\beta\left(r_{1}\right)=\beta\left(r_{2}\right)$, with the same wavevector. The interference is constructive or 
destructive in the plane of the observation, $\mathrm{P}$, if $\Delta \phi_{\mathrm{NL}}\left(\mathrm{r}_{1}\right)-\Delta \phi_{\mathrm{NL}}\left(\mathrm{r}_{2}\right)=\mathrm{p} \pi$, where $\mathrm{p}$ is an even or odd integer, respectively. This phenomenon is the origin of the appearance of diffraction rings (Dabby et al., 1970; Durbin et al., 1981).

\section{Experimental}

\subsection{Nanostructured semiconductors}

The CdSe/ZnS core-shell nanocrystal suspension was prepared by mixing poly(methyl methacrylate) PMMA-encapsulated CdSe/ZnS quantum dots with THF $\left(\mathrm{C}_{4} \mathrm{H}_{8} \mathrm{O}\right)$ solvent under constant magnetic stirring at a concentration of $(12-60) \mathrm{mg} / \mathrm{mL}$. The same procedure was applied for PMMA-encapsuled CdSe/ZnS core-shell particles using chloroform $\left(\mathrm{CHCl}_{3}\right)$ and toluene $\left(\mathrm{C}_{6} \mathrm{H}_{5} \mathrm{CH}_{3}\right)$. Evident Technologies (Evident, 2005) supplied the $\mathrm{CdSe} / \mathrm{ZnS}$ encapsulated in PMMA with a molecular weight of $74 \mu \mathrm{g} / \mathrm{nmol}$ and an average crystal diameter of $3.7 \mathrm{~nm}$ (Pilla et al., 2007), as well as samples of CdSe/ZnS suspended in toluene solution with a core size between 2.4-4.1 nm (Pilla et al. 2008) and CdSe/ZnS suspended in water $(2.6 \mu \mathrm{mol} / \mathrm{L}$ and core size $4.0 \mathrm{~nm})$.

Magic-sized CdSe/CdS nanocrystals were synthesized by combining the following aqueous solutions in a nitrogen atmosphere: an aqueous solution containing selenium dioxide $\left(\mathrm{SeO}_{2}\right)$ and sodium hydroxide in ultra-pure water was magnetically stirred to form $\mathrm{Na}_{2} \mathrm{SeO}_{3}$, and 1thioglycerol was immediately added to the solution; an aqueous solution containing cadmium acetate dihydrate in dimethyl formamide (DMF). The two solutions were then mixed. The function of thioglycerol was to limit nanocrystal growth by Ostwald ripening, and also to prevent aggregation and minimize surface dangling bonds, thereby decreasing the level of defects. This procedure was carried out at $80^{\circ} \mathrm{C}$ and yielded a CdSe/CdS based colloidal aqueous solution. The solution of magic-sized CdSe/CdS nanocrystals had a molar concentration of $3.5 \mu \mathrm{mol} / \mathrm{L}$ and a core size of $1.9 \mathrm{~nm}$.

\subsection{Thermal-optical measurements}

The thermo-optical properties of core-shell nanoparticle solutions were investigated by the TL method (Cruz et al., 2010; Pilla et al., 2007, 2008) and by TSPM (Pilla et al., 2009). TL transient measurements were performed in the mode-mismatched dual-beam (excitation and probe) configuration (Fig. 1(a-b)). A He-Ne laser $\left(\lambda_{\mathrm{p}}=632.8 \mathrm{~nm}\right)$ was used as the probe beam, and an Argon ion laser $\left(\lambda_{\mathrm{e}}=514.5 \mathrm{~nm}\right)$ or He-Ne $\left(\lambda_{\mathrm{e}}=594 \mathrm{~nm}\right)$ was used as the excitation beam. The excitation and probe beam radii at the sample were measured to be $\mathrm{w}_{\mathrm{e}}=(53 \pm 1) \mu \mathrm{m}$ at $514.5 \mathrm{~nm}\left(\right.$ or $\mathrm{w}_{\mathrm{e}}=(81 \pm 2) \mu \mathrm{m}$ at $\left.594 \mathrm{~nm}\right)$ and $\mathrm{w}_{1}=(172 \pm 3) \mu \mathrm{m}$, respectively. Absorption of the excitation beam generated a TL heat profile and induced a phase shift proportional to $\theta$. Modulation of the pump beam with a mechanical chopper allowed for time-resolved measurement. The transient curve was obtained from the weak probe beam, which counter-propagated in a nearly collinear with the excitation beam.

Figure 2 presents the experimental setup used for TSPM technique. In this case, an Argon ion laser $\left(\lambda_{\mathrm{e}}=514.5 \mathrm{~nm}\right)$ was used as the excitation beam. All measurements, as a function of laser beam power, were carried out with solutions in 2-mm glass cuvette that was positioned in the focal region of a lens with $20 \mathrm{~cm}$ focal length. 


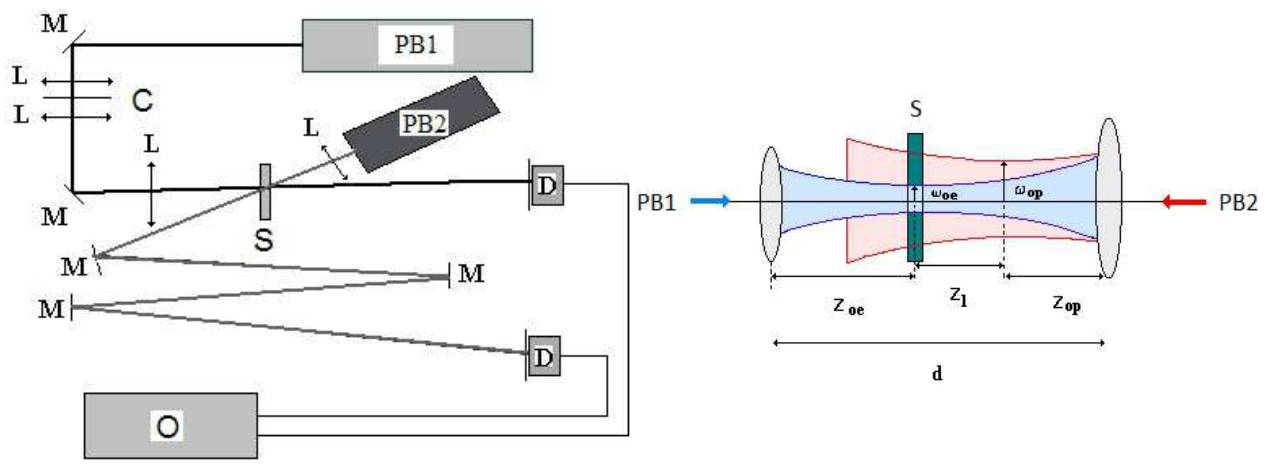

(a)

(b)

Fig. 1. (a) Schematic diagrams of the TL experimental configuration and (b) details of the geometric configuration of the probe (PB2) and pump (PB1) beams. Here M, L and C are mirror, convergent lens and chopper; $\mathrm{S}, \mathrm{D}$ and $\mathrm{O}$ are sample, detector and oscilloscope. $\mathrm{z}_{\mathrm{o}}$ and $w_{o}$ are the beam Rayleigh range focal lens and the radius for the pump (e) or probe (p) beams, respectively. $\mathrm{d}$ is the separation between the lens of pump and probe beams.
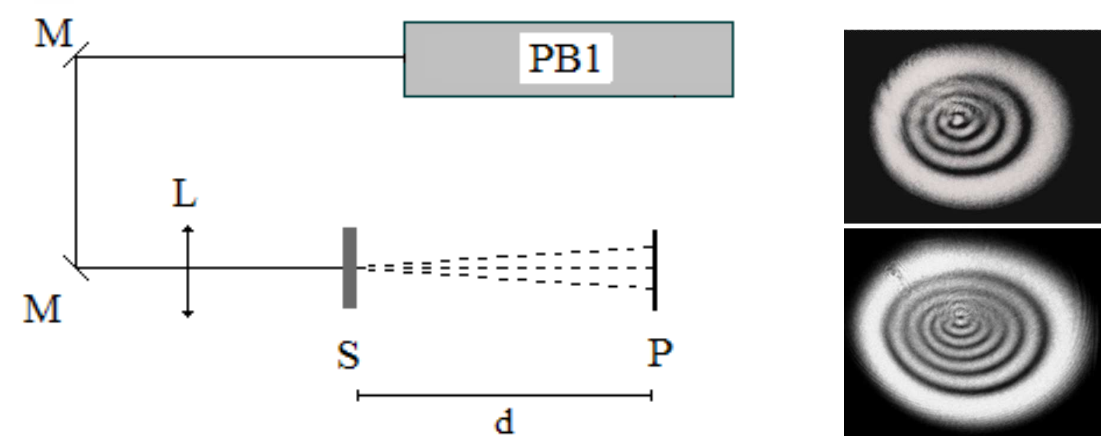

(a)

(b)

Fig. 2. Schematic diagrams of the thermal self-phase modulation (TSPM) experimental apparatus. Here $\mathrm{M}$ and $\mathrm{L}$ are mirror and convergent lens; $\mathrm{S}$ is sample. P indicates the observation plane, which shows the typical ring patterns for CdSe/ZnS QDs samples solutions at (a) $\alpha=$ $0.57 \mathrm{~cm}^{-1}$ and $\mathrm{P}_{\mathrm{e}} \approx 59 \mathrm{~mW}$; (b) $\alpha=0.35 \mathrm{~cm}^{-1}$ and $\mathrm{P}_{\mathrm{e}} \approx 88 \mathrm{~mW}, \lambda_{\mathrm{e}}=514.5 \mathrm{~nm}$ (Pilla et al., 2009).

\section{Results and discussions}

\subsection{Spectroscopic characterization of core-shell QDs}

The typical absorbance spectra of the core-shell CdSe/ZnS with different core sizes are present in Fig. 3, and their corresponding transitions can be found elsewhere (Norris et al., 1996; Valerini et al., 2005). The size of the core $\mathrm{D}_{\text {CdSe }}$ (in $\mathrm{nm}$ ) can be calculated by applying the value of the wavelength $\lambda$ (in $\mathrm{nm}$ ) for the first excitonic absorption peak of the sample, using the experimental fitting function obtained for the CdSe nanocrystal $(\mathrm{Yu}$ et al., 2003):

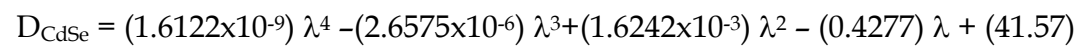




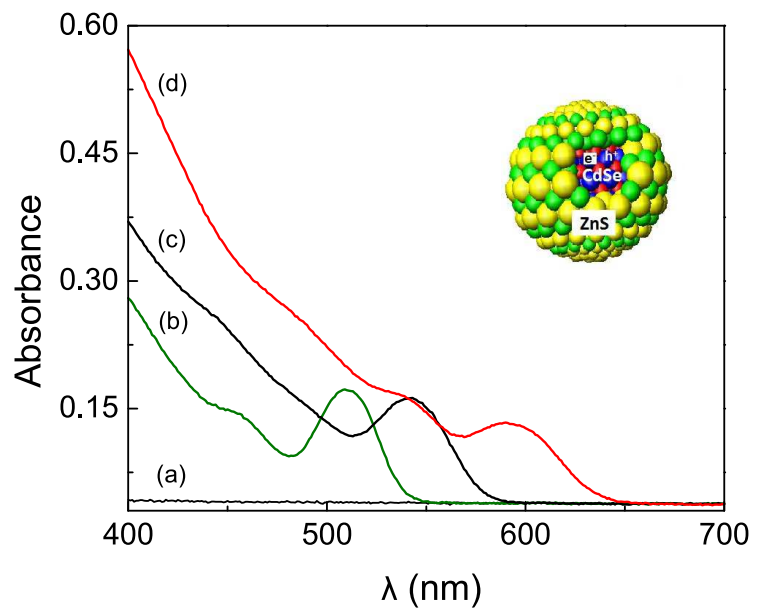

Fig. 3. Absorbance spectra for (a) toluene solvent and suspension of CdSe/ZnS in toluene for core sizes (b) $(2.4 \pm 0.2) \mathrm{nm}$, (c) $(2.9 \pm 0.5) \mathrm{nm}$ and (d) $(4.1 \pm 0.9) \mathrm{nm}$ at concentration $\sim 0.046 \mathrm{mg} / \mathrm{mL}$ (Pilla et al., 2008). The inset shows the nanostructure of the QD Type I, with a CdSe core surrounded by a ZnS shell. In this case electrons (e-) and holes $\left(\mathrm{h}^{+}\right)$are confined to the core of the core-shell QDs (Jasieniak et al., 2007; Kim et al., 2003).

The fluorescence spectra of the CdSe/ZnS are red-shifted as the core size increases (Fig. 4); the values obtained for $\left\langle\lambda_{\mathrm{em}}\right\rangle$ are $525 \mathrm{~nm}, 560 \mathrm{~nm}$ and $619 \mathrm{~nm}$ for $\alpha$ (at $514.5 \mathrm{~nm}$ ) of 0.31 , 0.199 and $0.35 \mathrm{~cm}^{-1}$, respectively. $\left\langle\lambda_{\mathrm{em}}>\right.$ values are dependent on QD concentrations (Pilla et al., 2008), solvents (Pilla et al., 2007) and aging effect (Cruz et al., 2010). For CdSe/CdS MSNs synthesized and studied here, the absorbance and fluorescence spectra are present in Fig. 5. The absorption band at $\sim 447 \mathrm{~nm}$ obtained is typical for core-shell CdSe/CdS MSNs

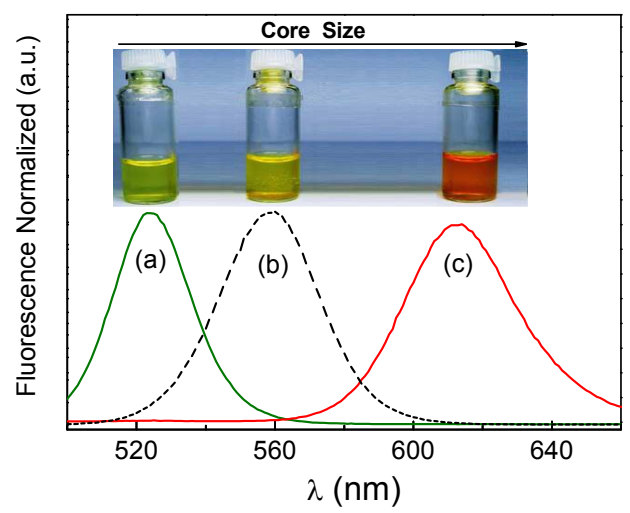

Fig. 4. Fluorescence spectra for CdSe/ZnS solutions as a function of the core sizes: (a) 2.4 $\mathrm{nm}$, (b) $2.9 \mathrm{~nm}$ and (c) $4.1 \mathrm{~nm}$. Fluorescence measurements were performed at $\lambda_{\mathrm{e}}=457 \mathrm{~nm}$ (Pilla et al., 2008). The colors of the solutions are illustrative. 
(Chen et al., 2008; Deng et al., 2010), and the value of $\left\langle\lambda_{\mathrm{em}}\right\rangle=588.9 \mathrm{~nm}$ for $\alpha=1.25 \mathrm{~cm}^{-1}$ at $514.5 \mathrm{~nm}$ was obtained from fluorescence measurement. Peaks related to longitudinal optical phonons (LO) and (2LO) at 206.6 and $411 \mathrm{~cm}^{-1}$ of the synthesized CdSe MSNs are clearly observable in the Raman spectrum shown in Fig. 5 (Nien et al., 2008). Another peak at $280 \mathrm{~cm}^{-1}$, related to the CdS vibrational mode, can also be seen (Leite \& Porto, 1966). The frequency of the bulk CdS LO phonon at $\sim 305 \mathrm{~cm}^{-1}$ decreases to $280-300 \mathrm{~cm}^{-1}$ in thin layers because of phonon confinement effects (Zou \& Weaver, 1999). Therefore, the peak observed at approximately $280 \mathrm{~cm}^{-1}$ can be attributed to the LO phonon of the CdS shell (Chen et al., 2010; Dzhagan et al., 2007; Singha et al., 2005) which confirms the formation of core-shell CdSe/CdS MSNs.

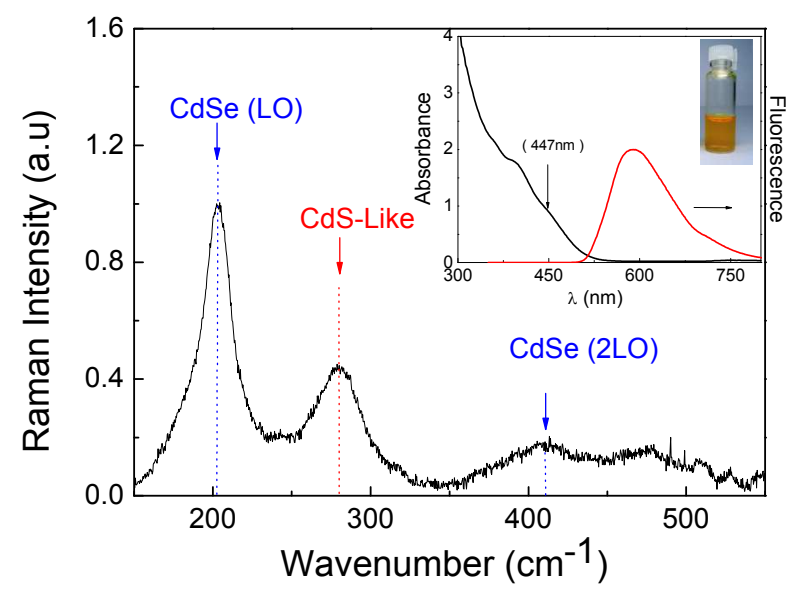

Fig. 5. Raman spectra for core-shell CdSe/CdS MSNs ( $\lambda_{\mathrm{e}}=514 \mathrm{~nm}$ and $\left.300 \mathrm{~K}\right)$. The inset shows the absorbance and fluorescence of CdSe $/ \mathrm{CdS}$ MSNs $\left(\lambda_{\mathrm{e}}=457.9 \mathrm{~nm}\right.$ for fluorescence).

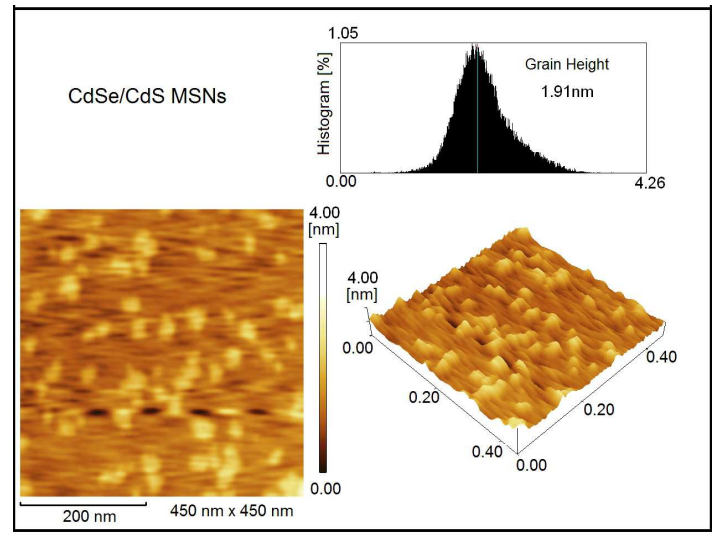

Fig. 6. Two-dimensional and three-dimensional AFM images and corresponding histograms revealing height and size dispersions of the core-shell CdSe/CdS MSNs. 
The size and dispersions of CdSe/CdS MNSs were determined by examining AFM bidimensional and tri-dimensional images and their corresponding histograms. The average core sizes ( $\mathrm{D}_{\mathrm{CdS}}$ ) of the CdSe/CdS MSNs were determined from the peaks (Ong \& Sokolov, 2007; Rao et al., 2007) of the histogram (Fig. 6). The average size of the CdSe/CdS MNSs (1.9 $\pm 0.4) \mathrm{nm}$, determined by AFM measurements, is in good agreement with the values obtained from Eq. (7) and the absorption spectrum of the Fig. 5 (Yu et al., 2003).

\subsection{Thermal diffusivity and $\varphi \mathrm{dn} / \mathrm{dT}$ as a function of concentration, solvent and core size}

TL transient signals for the PMMA-encapsulated CdSe/ZnS nanocrystals (Fig. 7) were fit to Eq. (3), which supplies $\tau_{\mathrm{c}}$ and the amplitude parameter $\theta$. From $\mathrm{D}=\mathrm{w}_{\mathrm{e}}{ }^{2} / 4 \tau_{\mathrm{c}}$ and the measured value $w_{e}$, the average values of $D$ for the core-shell nanocrystal solutions can be determined as a function of CdSe/ZnS PMMA concentration. These values are shown in Table 1 for the three different solvents. The thermal diffusivity results are in agreement with typical values obtained for pure solvents (Pilla et al., 2007) and for PMMA, which has a reported thermal diffusivity value of $\mathrm{D} \sim 1.0 \times 10^{-3} \mathrm{~cm}^{2} / \mathrm{s}$ (Agari et al., 1997; Goyanes et al., 2001). No significant variation in the $\mathrm{D}$ values as a function of either the concentration or the QD size (Table 2) was observed. The thermal parameters $\Theta=-\theta / P_{e} \alpha L_{\text {eff }}$ of the core-shell quantum dot suspensions were determined through transient thermal lens measurements. Using Eq. $1 \mathrm{~b}$ with $\mathrm{K}=0.12$ $\mathrm{W} / \mathrm{mK}$ (Nikogosyan, 1997), we obtained an average value of $\varphi \mathrm{dn} / \mathrm{dT}=-1.8 \times 10^{-4} \mathrm{~K}^{-1}$ at $\lambda_{\mathrm{e}}=$ $594 \mathrm{~nm}$ and $\lambda_{\mathrm{p}}=632.8 \mathrm{~nm}$ for the nanocrystal suspended in chloroform in the concentration range of (12-60) $\mathrm{mg} / \mathrm{mL}$. Table 1 shows the average values of $\varphi \mathrm{dn} / \mathrm{dT}$ for PMMAencapsulated CdSe/ZnS suspended in toluene and THF with $\mathrm{K}=0.135 \mathrm{~W} / \mathrm{mK}$ (Nikogosyan, 1997) and $\mathrm{K}=0.14 \mathrm{~W} / \mathrm{mK}$ (Ge et al., 2005). The transient curves obtained with the TL technique indicate that TL promotes defocusing of the probe beam in the far field; i.e., $\mathrm{dn} / \mathrm{dT}$ is negative.

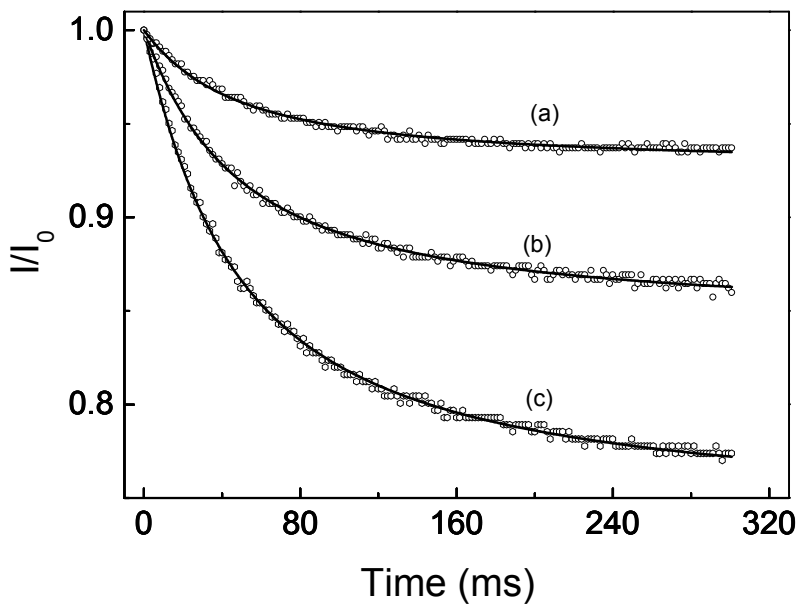

Fig. 7. Transient TL signal for PMMA-encapsulated CdSe/ZnS suspended in chloroform $\left(\mathrm{CHCl}_{3}\right)$ at (a) 12, (b) 20, (c) $40 \mathrm{mg} / \mathrm{mL}\left(\lambda_{\mathrm{e}}=594 \mathrm{~nm}, \mathrm{P}_{\mathrm{e}}=1.03 \mathrm{~mW}\right.$ and $\left.\lambda_{\mathrm{p}}=632.8 \mathrm{~nm}\right)$. Using $\theta$ and $\tau_{\mathrm{c}}$ results by fitting with Eq. $3, \mathrm{D}\left(10^{-3} \mathrm{~cm}^{2} / \mathrm{s}\right)$ and $-\varphi \mathrm{dn} / \mathrm{dT}\left(10^{-4} \mathrm{~K}^{-1}\right)$ values obtained were the following: (a) $(0.84 \pm 0.02)$ and 1.59 ; (b) $(0.84 \pm 0.02)$ and 1.83 ; and (c) $(0.83 \pm 0.01)$ and 2.27 , respectively. 
In order to calculate $\varphi=\Theta / \Theta \mathrm{s}$, where $\Theta_{\mathrm{S}}$ is the value for the solvent presented in Table 1 , we used Eq. 4a and assumed a negligible fluorescence for the solvent (chloroform, THF or toluene) in the TL measurements, i.e., $\varphi_{S}=1$. The calculated value of $\varphi$ is $(0.30 \pm 0.04)$ for the core-shell suspended in chloroform. For the PMMA-encapsulated CdSe/ZnS suspended in THF or toluene, the $\varphi$ values are shown in Table 1. Using the values of $\varphi$ obtained for the core-shell suspended in THF, chloroform and toluene (Table 1), we obtained $\mathrm{d} n / \mathrm{d} T=-4.9$, -6.0 and $-5.3 \times 10^{-4} \mathrm{~K}^{-1}$, respectively. These values are in agreement with those reported in the literature for THF, chloroform and toluene solvents (El-Kashef, 2002; Nikogosyan, 1997).

\begin{tabular}{|c|c|c|c|c|}
\hline $\begin{array}{c}\text { PMMA } \\
\text { CdSe/ZnS }\end{array}$ & $\begin{array}{c}\Theta s \\
\left(W^{-1}\right)\end{array}$ & $\begin{array}{c}\mathrm{D} \\
\left(10^{-3} \mathrm{~cm}^{2} / \mathrm{s}\right)\end{array}$ & $\begin{array}{l}-\varphi d n / d T \\
\left(10^{-4} \mathrm{~K}^{-1}\right)\end{array}$ & $\varphi$ \\
\hline THF & 5644 & $(1.00 \pm 0.03)$ & $(1.7 \pm 0.4)$ & $(0.35 \pm 0.07)$ \\
\hline Chloroform & 8165 & $(0.84 \pm 0.02)$ & $(1.8 \pm 0.4)$ & $(0.30 \pm 0.04)$ \\
\hline Toluene & 6564 & $(1.01 \pm 0.03)$ & $(2.6 \pm 0.3)$ & $(0.49 \pm 0.03)$ \\
\hline
\end{tabular}

Table 1. TL results for PMMA-encapsulated CdSe/ZnS suspended in different solvents $\left(\lambda_{\mathrm{e}}=594 \mathrm{~nm}\right.$ and $\left.\lambda_{\mathrm{p}}=632.8 \mathrm{~nm}\right)$. Average values obtained for different concentrations $(12-60) \mathrm{mg} / \mathrm{mL}$.

The temperature coefficient of the refractive index $(d n / d T)$ is affected by two competing factors: thermal expansion, which leads to decreased density and causes the refractive index to decrease because of increased inter-molecular spacing, and increased electronic polarizability, which causes the refractive index to gradually increase. In liquid and film samples, $d n / d T$ is usually negative, indicating that expansion is the dominant contributor. For example, for common solvents such as toluene and water, the values of $d n / d T$ are -5.4 and $-0.8 \times 10^{-4} \mathrm{~K}^{-1}$, respectively (Dovichi \& Harris, 1979; El-Kashef, 2002; Kohanzadeh et al., 1973; Nikogosyan, 1997). For glasses and transparent crystals, $d n / d T$ can be either positive or negative, depending on the glass (Andrade et al., 2003). In general, $d n / d T$ is negative for highly expansive and loosely bound networks and positive for tightly bound networks. Polymers usually have high expansion coefficients and, therefore, negative values of $d n / d T$ (Pilla et al., 2002).

\begin{tabular}{lcccc}
\hline \multicolumn{1}{c}{ CdSe/ZnS } & $\begin{array}{c}\text { core size } \\
(\mathrm{nm})\end{array}$ & $\begin{array}{c}\mathrm{D} \\
\left(10^{-3} \mathrm{~cm}^{2} / \mathrm{s}\right)\end{array}$ & $\begin{array}{c}-\varphi \mathrm{dn} / \mathrm{dT}^{*} \\
\left(10^{-4} \mathrm{~K}^{-1}\right)\end{array}$ & $\varphi^{*}$ \\
\hline THF & $3.5 \pm 0.8$ & $1.00 \pm 0.03$ & $(2.2 \pm 0.2)$ & $(0.44 \pm 0.04)$ \\
Toluene & $4.1 \pm 0.9$ & $0.99 \pm 0.01$ & $(3.4 \pm 0.6)$ & $(0.61 \pm 0.06)$ \\
Toluene & $2.9 \pm 0.5$ & $1.01 \pm 0.06$ & $(2.7 \pm 0.3)$ & $(0.52 \pm 0.05)$ \\
Toluene & $2.4 \pm 0.2$ & $0.94 \pm 0.03$ & $(2.1 \pm 0.3)$ & $(0.37 \pm 0.06)$ \\
\hline
\end{tabular}

Table 2. TL and TSPM results for suspended CdSe/ZnS with different core sizes $\left(\lambda_{\mathrm{e}}=514.5\right.$ $n m$ and $\lambda_{\mathrm{p}}=632.8 \mathrm{~nm}$ ). ${ }^{*}$ Average values obtained for TL and TSPM methods (Pilla et al., 2009)

For CdSe/ZnS nanocrystal solution suspended in THF with $\alpha=(0.57 \pm 0.03) \mathrm{cm}^{-1}$ at 514.5 $\mathrm{nm}$, the value for $\varphi \mathrm{dn} / \mathrm{dT}=-(2.1 \pm 0.2) \mathrm{K}^{-1}$ was obtained from the TL measurements. Alternatively, using a single laser beam for the excitation of the core-shell QD solution at $\lambda_{\mathrm{e}}$ $=514.5 \mathrm{~nm}$, we observed the formation of ring patterns caused by thermal spatial self-phase 
modulation (TSPM) effects ( $\Delta \phi_{\mathrm{TH}}$ described by Eq. 1). Typical ring patterns were observed when the sample was positioned at the focus of the pump beam (Pilla et al., 2009). The numbers of rings $(\mathrm{N})$ as a function of the beam power $\left(P_{e}\right)$ are shown in Fig. 8 for the QDs suspended in different solvents at different concentrations. The experimental $N$ versus $P_{e}$ results were fit using a linear equation, and the values of the angular coefficients, $A$, of the fitting line were determined. Using Eq. (5) and the $K$ values of the solvents, the value of $|\varphi \mathrm{d} n / \mathrm{d} T|=(2.2 \pm 0.2) \times 10^{-4} \mathrm{~K}^{-1}$ was determined for PMMA-encapsulated CdSe/ZnS suspended in THF. For QDs suspended in toluene with different core sizes, Table 2 presents the average values for $\varphi \mathrm{d} n / \mathrm{d} T$ determined by the TL and TSPM methods, which are in good agreement. The dynamic response time of ring formation for the CdSe/ZnS soltution (at $\lambda_{\mathrm{e}}=$ $514.5 \mathrm{~nm}, \mathrm{P}_{\mathrm{e}} \approx 92 \mathrm{~mW}$ ) is shown in Fig. 8. This result was obtained with the detector in the far field ( $116 \mathrm{~cm}$ after the sample), and an iris placed in front of the detector, in the position of the formation of the first ring.

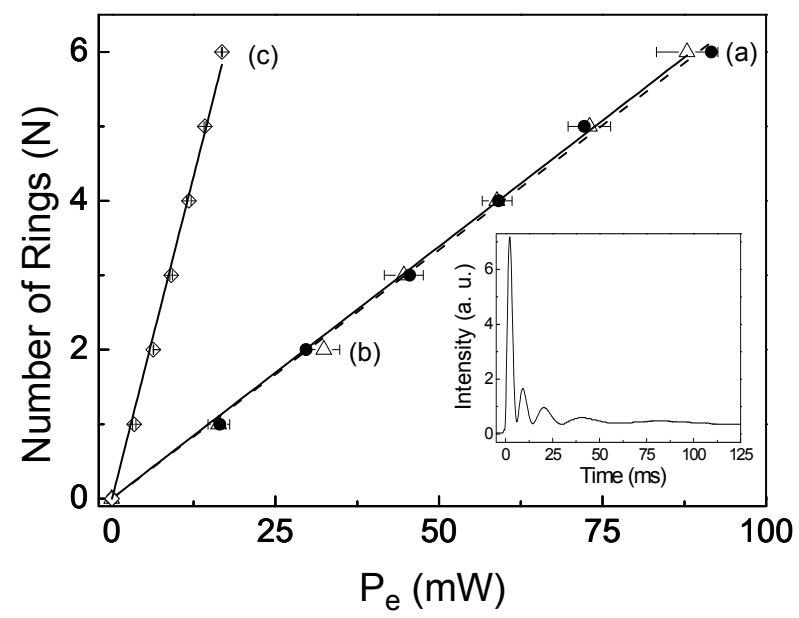

Fig. 8. Number of rings $(\mathrm{N})$ as a function of excitation beam power $\left(\mathrm{P}_{\mathrm{e}}\right)$ for encapsulatedPMMA CdSe $/ Z n S$ (a) and CdSe $/ Z n S(b-c)$ at $\lambda_{\mathrm{e}}=514.5 \mathrm{~nm}$. The linear trend was obtained by fitting the equation $\mathrm{N}=\mathrm{A}^{*} \mathrm{P}_{\mathrm{e}}$, where obtained $A$ values are: (a) $(66.9 \pm 0.7) \mathrm{W}^{-1}$ and $\alpha=0.57$ $\mathrm{cm}^{-1}$; (b) $(67.7 \pm 0.7) \mathrm{W}^{-1}$ and $\alpha=0.35 \mathrm{~cm}^{-1}$; and (c) $(347 \pm 5) \mathrm{W}^{-1}$ and $\alpha=2.86 \mathrm{~cm}^{-1}$ (Pilla et al., 2009). The inset shows the time evolution of ring formation for CdSe/ZnS QDs.

Several transverse effects can be observed when an intense laser beam propagates through a nonlinear medium (Dabby et al., 1970; Durbin et al., 1981; Ono \& Saito, 1999; Valley et al., 1990). The laser-matter interaction modifies the spatial profile of the incident beam so strongly that rings surrounding the central spot of the beam may be observed in the far-field region. The ring structure exhibits circular symmetry when distortion caused by thermal convection is absent or negligible (Dabby et al., 1970; Whinnery et al., 1967). Spatial self-phase modulation (SPM) may be described by Kirchhoff's diffraction integral, applied to the propagation of a laser beam inside a nonlinear medium (Catunda \& Cury, 1990; Pilla et al., 2003). The effects of the nonlinearity include induced phase variation caused by the transverse variation of the 
refractive index and intensity-dependent absorption (Petrov et al., 1994). The literature describes studies of SPM effects in several materials, including liquid crystals, crystals, glasses, transparent media, and polymers (Du \& Liu, 1993; Durbin et al., 1981; Torruellas et al., 1995; Yang et al., 2005). SPM effects have been observed in semiconductor-doped glasses in studies on fast-electronic nonlinearity (Hickmann et al., 1992) and thermal nonlinearity (Petrov et al., 1994). Other phenomena related to SPM include self-focusing and self-defocusing, the generation of spatial solitons, simultaneous spatial-temporal focusing, and self-guided propagation (Catunda \& Cury, 1990; Khitrova et al., 1993).

Thermal spatial self-phase modulation can be predicted numerically using the Kirchhoff Diffraction Integral (Pilla et al., 2003). We consider the diffraction of a linearly polarized monochromatic plane wave in a finite region on the output sample face ( $S$ plane), where the geometrical points are described by the coordinates $\left(\mathrm{x}_{1}, \mathrm{y}_{1}, \mathrm{z}\right)$. The intensity of the excitation beam is proportional to $\left|\varepsilon\left(r_{2}\right)\right|^{2}$, and their spatial profiles as a function of the pump beam intensity are presented in Fig. 9 and 10 for two different concentrations. Here, $\rho_{2}=r_{2} / w_{2}$, where $\mathrm{w}_{2}$ is the probe beam waist in the observation plane. All curves in Figs. 9-10 are normalized to the maximum intensity, which occurs at $\rho_{2}=0$ for $P_{e}=0 \mathrm{~mW}$.

(b)
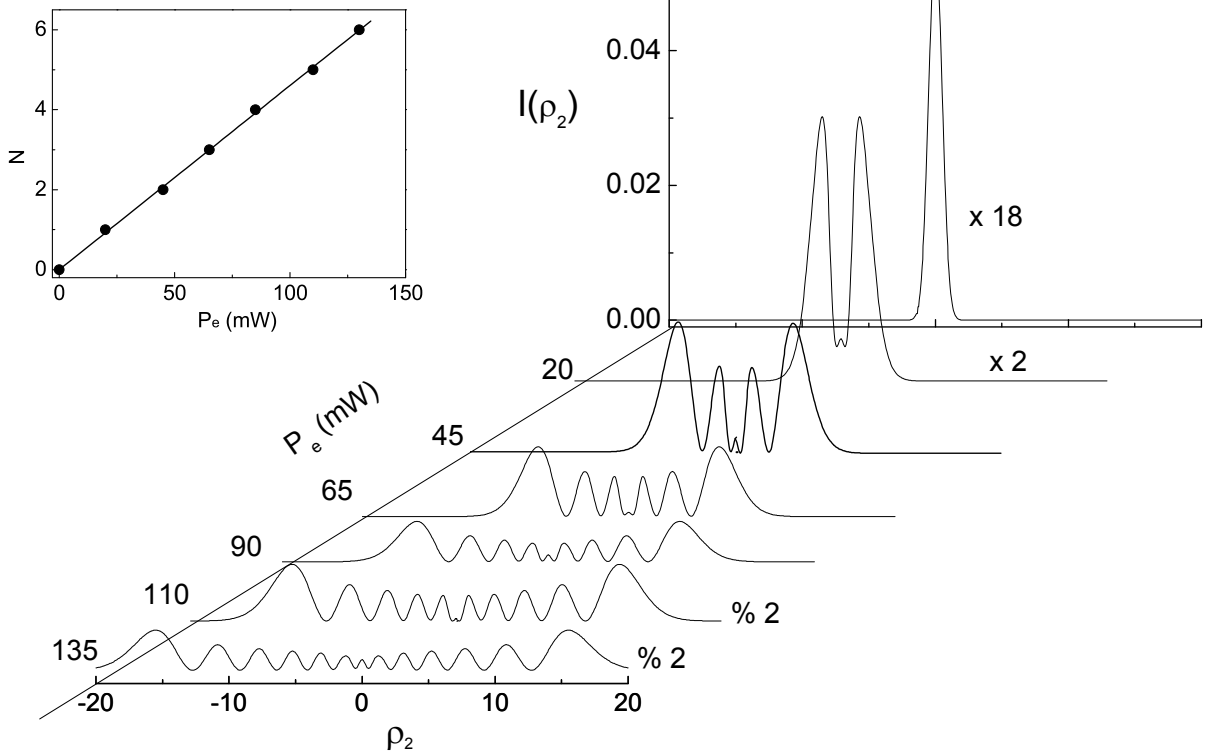

Fig. 9. (a) Numerical predictions of the excitation beam intensity profile, $\mathrm{I}\left(\rho_{2}\right)$, as a function of $\rho_{2}=\mathrm{r}_{2} / \mathrm{w}_{2}$, using Eq. (2) and (1a-b), with $\alpha=0.35 \mathrm{~cm}^{-1}, \mathrm{dn} / \mathrm{dT}=-5.4 \times 10^{-4} \mathrm{~K}^{-1}$, and $\lambda_{\mathrm{p}}=514.5$ $\mathrm{nm}$. The curves are normalized to the value corresponding to $\rho_{2}=0$ at $P_{\mathrm{e}}=0 \mathrm{~mW}$. (b) Number of dark Rings $(\mathrm{N})$ versus $\mathrm{P}_{\mathrm{e}}(\mathrm{mW})$ obtained from numerical calculations. The linear trend was obtained by fitting the equation $\mathrm{N}=0.05 * \mathrm{P}_{\mathrm{e}}$. 
Figures 9 (b) and 10 (b) shows $N$ versus $P_{e}$ obtained from numerical calculations; the linear fits obtained are in good agreement with the experimental measurements (Fig. 8) on CdSe/ZnS core-shell nanocrystals suspended in toluene.

In Table 2, we present the $\varphi d n / d T$ values obtained for CdSe/ZnS solutions suspended in toluene as a function of core sizes $(\sim 2.4-4.1 \mathrm{~nm})$. The experimental measurements were performed by applying the TL and TSPM techniques at $\lambda_{e}=514.5 \mathrm{~nm}$. Supposing a constant $d n / d T$ parameter, we obtained $\varphi$ values that are dependent on the nanocrystal core size. $\varphi$ increases with the increasing size of the nanoparticle cores $(\sim 39 \%)$, and the best result was obtained for the smallest analyzed core $(\sim 2.4 \mathrm{~nm})$. In fact, the obtained dependence of the $\varphi$ values could be attributed to quantum confinement effects, which are dependent on the size of the semiconductor nanocrystal relative to their exciton Bohr radius ( $5.3 \mathrm{~nm}$ for CdSe) (Katz et al., 2002; Nirmal et al., 1994; Prasad, 2004). The CdSe/ZnS nanocrystals studied (Table 2) are in a strong quantum confinement regime. In this form, thermally induced depopulation of the lowest electronic states is inhibited when the quantum dot size is reduced, because the energy spacing of the atom-like states is greater than the available thermal energy (Klimov, 2003).

(b)
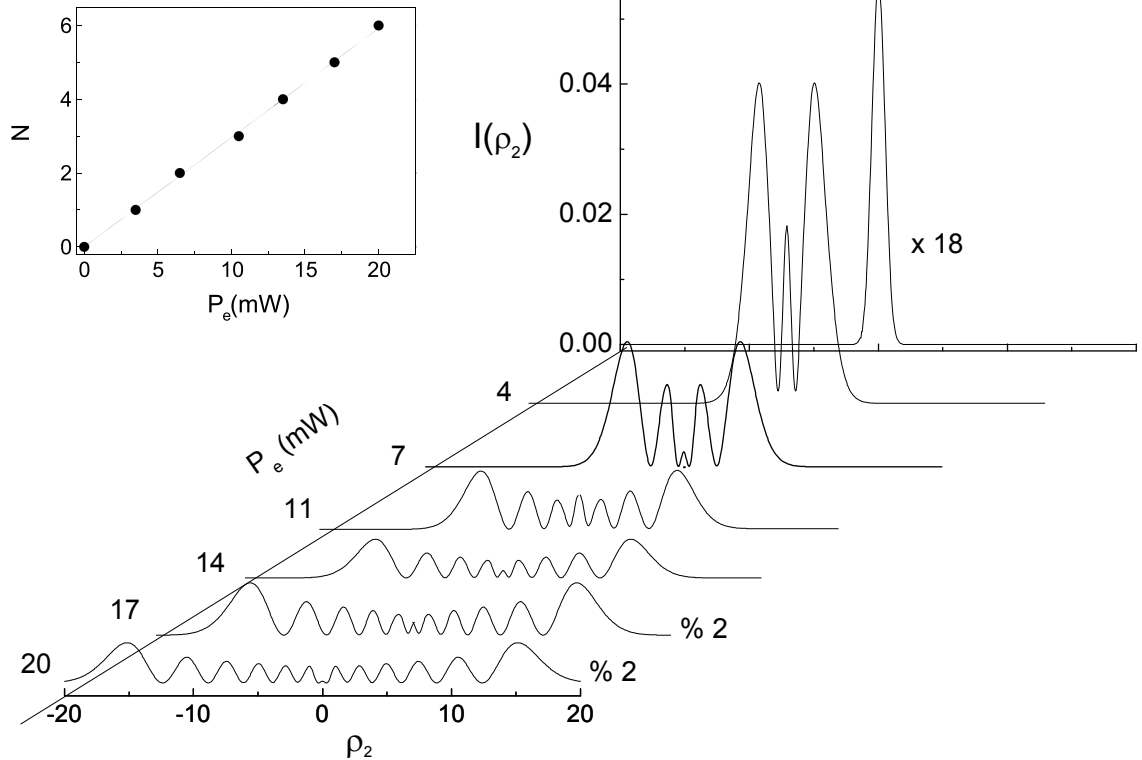

Fig. 10. (a) Numerical predictions of the excitation beam intensity profile, $I\left(\rho_{2}\right)$, as a function of $\rho_{2}=\mathrm{r}_{2} / \mathrm{w}_{2}$, using Eq. (2) and (1a-b), with $\alpha=2.86 \mathrm{~cm}^{-1}, \mathrm{dn} / \mathrm{dT}=-5.4 \times 10^{-4} \mathrm{~K}^{-1}$, and $\lambda_{\mathrm{p}}=514.5$ $\mathrm{nm}$. (b) Number of dark Rings (N) versus $\mathrm{P}_{\mathrm{e}}(\mathrm{mW})$ obtained from numerical calculations. The linear trend was obtained by fitting the equation $\mathrm{N}=0.30 * \mathrm{P}$. 


\subsection{Fluorescence quantum efficiency: Measurements as a function of concentration, solvent and core size}

To determine the radiative quantum efficiency, $\eta$, solvents of negligible fluorescence were used (S). Thus, for all solvents, the absorbed energy is converted into heat in the material, i.e., $\varphi_{S}=1\left(\eta_{S}=0\right)$. Applying Eq. $4(\mathrm{~b})$, it is possible to obtain the following expression:

$$
\eta=(1-\varphi)\left(\frac{<\lambda_{e m}>}{\lambda_{e}}\right)
$$

The radiative quantum efficiency values for core-shell colloidal nanocrystal solutions are presented in Table 3. The $\eta$ results are presented for core-shell PMMA-encapsulated $\mathrm{CdSe} / \mathrm{ZnS}$ suspended in toluene, chloroform and THF, for CdSe/ZnS suspended in toluene, and for the aqueous colloidal suspension of $\mathrm{CdSe} / \mathrm{ZnS}$ and $\mathrm{CdSe} / \mathrm{CdS}$, respectively. For PMMA-encapsulated CdSe/ZnS, $\eta$ is dependent on concentration (Pilla et al., 2007), and the aging effect (Cruz et al., 2010). The value of $\eta$ decreased by $\sim 60 \%$ over a 200-hour interval of UV-vis TL measurements (Cruz et al., 2010). For CdSe/ZnS QDs, the $\eta$ values were dependent on the core size and concentration (Pilla et al. 2008); for CdSe/ZnS suspended in toluene, the $\eta$ results were nearly independent of the pump wavelength (335-543) nm (Cruz et al., 2010). The values of $\eta$ increased for solutions without PMMA, and it can be concluded that PMMA plays a significant role in the fluorescence quenching of the complex CdSe/ZnS PMMA solution (Pilla et al., 2008).

\begin{tabular}{lccc}
\hline \multicolumn{1}{c}{ Core/shell } & $\begin{array}{c}\text { Core Size } \\
(\mathrm{nm})\end{array}$ & Concentration & $\eta$ \\
\hline PMMA-CdSe/ZnS chloroform $^{1}$ & $(3.7 \pm 0.9)$ & $(12-60) \mathrm{g} / \mathrm{L}$ & $(0.71 \pm 0.03)$ \\
PMMA- CdSe/ZnS THF $^{1}$ & $(3.5 \pm 0.8)$ & $(12-60) \mathrm{g} / \mathrm{L}$ & $(0.65 \pm 0.07)$ \\
PMMA-CdSe/ZnS toluene $^{1}$ & $(3.8 \pm 0.9)$ & $(12-60) \mathrm{g} / \mathrm{L}$ & $(0.50 \pm 0.03)$ \\
CdSe/ZnS toluene $^{2}$ & $(2.4 \pm 0.2)$ & $3.14 \mu \mathrm{mol} / \mathrm{L}$ & $(0.76 \pm 0.02)$ \\
CdSe/ZnS water $^{\text {CdSe/CdS water }}$ & $(4.0 \pm 0.8)$ & $2.6 \mu \mathrm{mol} / \mathrm{L}$ & $(0.61 \pm 0.04)$ \\
\hline
\end{tabular}

${ }^{1}$ Average values obtained for different concentrations (12-60) $\mathrm{mg} / \mathrm{mL}$ (Pilla et al., 2007).

${ }^{2}$ Average values at UV-vis excitation range (335-528) nm (Cruz et al., 2010).

Table 3. Core-shell QDs suspended in toluene, chloroform, THF or aqueous solutions.

In addition, radiative quantum efficiency values are presented for CdSe/ZnS and $\mathrm{CdSe} / \mathrm{CdS}$ colloidal aqueous solutions, and high quantum efficiencies were obtained. As a comparison, for Rhodamine B dye dissolved in methanol, the $\eta$ values decreased from 0.8 to $\sim 0.1$ with increasing concentration in the range of $\sim 10^{-5}-10^{-3}$ molar (Bindhu et al., 1996). For $\mathrm{CdSe} / \mathrm{ZnSe}$ core/shell nanocrystals suspended in organic solvents, the values of $\eta=(0.60$ 0.85 ) were obtained, as a result of the thicker deposit shell concentration (Reiss et al., 2002); quantum yield values were reported as 0.4-0.6 for CdSe QDs (core-sizes between 2.8 and 5.0 nm), 0.55 for CdSe/ZnSe/ZnS (Donegá et al., 2006) and up to 0.70 for CdTe/CdS MSNs aqueous colloidal solution (Deng et al., 2010). 


\section{Conclusions}

A review of the thermo-optical characterization of CdSe/ZnS core-shell nanocrystal solutions was performed. The Thermal Lens (TL) technique was used, and the thermal selfphase Modulation (TSPM) technique was adopted as the simplest alternative method. The main parameter determined was $\varphi d n / d T$; this parameter permitted the calculation of the fraction of thermal load $(\varphi)$ for different core-sizes of QDs suspended in different solvents. The thermo-optical results obtained using TSPM and predicted numerically using the Kirchhoff Diffraction Integral are in good agreement with those obtained from the TL technique. The thermal diffusivity parameters were characteristic of the solvents used to suspend the core-shell QDs. The radiative quantum efficiency, $\eta$, for CdSe/ZnS core-shells and its dependence on the concentration, solvent, core size and aging effects were reported. In addition, the thermo-optical characterization of $\mathrm{CdSe} / \mathrm{ZnS}$ and $\mathrm{CdSe} / \mathrm{CdS}$ core-shell nanocrystals suspended in aqueous solution is presented as a result of interest for applications in nanobiotechnology. As future research trends we could highlight the application of the Thermal Lens technique for the characterization of fluorescent nanostructures functionalized for biomarker applications.

\section{Acknowledgement}

This research was supported by CNPq (Proc. 473951/2010-0), FAPESP (Proc. 2006/01277-2), FAPEMIG (Proc. APQ-02878-09 and Proc. CEX-APQ-00576-11) and Nanobiotec-Brazil Network (Proc. 04/CII-2008).

\section{References}

Agari, Y.; Ueda, A.; Omura, Y. \& Nagai, S. (1997). Thermal Diffusivity and Conductivity of PMMA/PC Blends. Polymer Vol. 38, N. 4, pp. 801-807, ISSN 0032-3861.

Alves, L. P.; Pilla, V.; Murgo, D. O. A. \& Munin, E. (2010). Core-shell Quantum Dots Tailor the Fluorescence of Dental Resin Composites. Journal of Dentistry Vol. 38, N. 2, pp. 149-152, ISSN 0300-5712.

Andrade, A. A.; Catunda, T.; Lebullenger, R.; Hernandes, A. C. \& Baesso, M. L. (1998). TimeResolved Study of Thermal and Electronic Nonlinearities in $\mathrm{Nd}^{+3}$ doped Fluoride Glasses. Electronics Letters Vol. 34, N. 1, pp. 117-119, ISSN 0013-5194.

Andrade, A. A.; Lima, S. M.; Pilla, V.; Sampaio, J. A.; Catunda, T. \& Baesso, M. L. (2003). Fluorescence Quantum Efficiency Measurements using the Thermal Lens Technique. Review of Scientific Instruments Vol. 74, N. 1, pp. 857-859, ISSN 00346748 .

Baesso, M. L.; Shen, J. \& Snook, R. D. (1994). Mode-mismatched Thermal Lens Determination of Temperature Coefficient of Optical Path Length in Soda Lime Glass at different Wavelengths. Journal of Applied Physics Vol. 75, N. 8, pp. 37323737, ISSN 0021-8979.

Baker, D.R. \& Kamat, P.V. (2010). Tuning the Emission of CdSe Quantum Dots by Controlled Trap Enhancement. Langmuir Vol. 26 N. 13, pp. 11272-11276, ISSN 07437463. 
Banerjee, R.; Jayakrishnan, R. \& Ayyub, P. (2000). Effect of the Size-Induced Structural Transformation on the Band Gap in CdS Nanoparticles. Journal of Physics: Condensed Matter Vol.12, N. 50, pp. 10647-10654, ISSN 0953-8984.

Berthoud, T.; Delorme, N. \& Mauchien, P. (1985). Beam Geometry Optimization in DualBeam Thermal Lensing Spectrometry. Analytical Chemistry Vol. 57, N. 7, pp. 12161219, ISSN 0003-2700.

Bindhu, C.V.; Harilal, S. S.; Varier, G. K.; Issac, R. C.; Nampoori, V. P. N. \& Vallabhan, C. P. G. (1996). Measurement of the Absolute Fluorescence Quantum Yield of Rhodamine B Solution using a Dual-Beam Thermal Lens Technique. Journal of Physics D Applied Physics Vol 29, N. 4, pp. 1074-1079, ISSN 0022-3727.

Bruchez Jr., M.; Moronne, M.; Gin, P.; Weiss, S. \& Alivisatos, A. P. (1998). Semiconductor Nanocrystals as Fluorescent Biological Labels. Science. Vol. 281, N. 5385, pp. 20132016, ISSN 0036-8075.

Catunda, T. \& Cury, L. A. (1990). Transverse Self-Phase Modulation in Ruby and $\mathrm{GdAlO}_{3}$ : $\mathrm{Cr}^{+3}$ Crystals. Journal of the Optical Society of America B Vol. 7, N. 8, pp. 1445-1455, ISSN 0740-3224.

Catunda, T.; Baesso, M. L.; Messaddeq, Y. \& Aegerter, M. A. (1997). Time-resolved Z-scan and Thermal Lens Measurements in $\mathrm{Er}^{+3}$ and $\mathrm{Nd}^{+3}$ doped Fluoroindate Glasses. Journal of Non-Crystalline Solids Vol. 213-214, pp. 225-230, ISSN 0022-3093.

Chen, X.; Samia, A. C. S.; Lou, Y. \& Burda, C. (2005). Investigation of the Crystallization Process in $2 \mathrm{~nm}$ CdSe Quantum Dots. Journal of the American Chemical Society V. 127, N. 12, pp. 4372-4375, ISSN 0002-7863.

Chen, Y.; Vela, J.; Htoon, H.; Casson, J. L.; Werder, D. J.; Bussian, D. A.; Klimov, V. I. \& Hollingsworth, J. A. (2008). Giant Multishell CdSe Nanocrystal Quantum Dots with Suppressed Blinking. Journal of the American Chemical Society, Vol. 130, N. 15, pp. 5026-5027, ISSN 0002-7863.

Chen, I. C.; Weng, C. L.; Lin, C. H. \& Tsai, Y. C. (2010). Low-frequency Raman Scattering from Acoustic Vibrations of Spherical CdSe/CdS Nanoparticles. Journal of Applied Physics Vol. 108, N. 8, pp. 083530 (1-9), ISSN 0021-8979.

Cruz, R. A.; Pilla, V. \& Catunda, T. (2010). Quantum Yield Excitation Spectrum (UV-visible) of CdSe/ZnS Core-Shell Quantum Dots by Thermal Lens Spectrometry. Journal of Applied Physics Vol. 107, N. 8, pp. 083504 (1-6), ISSN 0021-8979.

Dabbousi, B. O.; Rodrigues-Viejo, J.; Mikulec, F. V., Heine, J. R., Mattoussi, H.; Ober, R.; Jensen, K. F. \& Bawendi, M. G. (1997). (CdSe)ZnS Core-Shell Quantum Dots: Synthesis and Characterization of a Size Series of Highly Luminescent Nanocrystallites. The Journal of Physical Chemistry B Vol. 101, N. 46, pp. 9463-9475, ISSN 1520-6106.

Dabby, F. W.; Gustafson, T. K.; Whinnery, J. R.; Kohanzadeh, Y. \& Kelley, P.L. (1970). Thermally Self-Induced Phase Modulation of Laser Beams. Applied Physics Letters Vol. 16, N. 9, pp. 362-365, ISSN 0003-6951.

Dagtepe, P.; Chikan, V.; Jasinski, J. \& Leppert, V. J. (2007). Quantized Growth of CdTe Quantum Dots; Observation of Magic-Sized CdTe Quantum Dots. The Journal of Physical Chemistry C Vol. 111, N. 41, pp. 14977-14983, ISSN 1932-7447.

Dagtepe, P. \& Chikan, V. (2010). Quantized Ostwald ripening of Colloidal Nanoparticles. The Journal of Physical Chemistry C Vol. 114 , N. 39 , pp. 16263-16269, ISSN 1932-7447. 
Deng, Z.; Schulz, O.; Lin, S.; Ding, B.; Liu, X., Wei, X., Ros, R., Yan, H. \& Liu, Y. (2010). Aqueous Synthesis of Zinc Blende CdTe/CdS Magic-Core/Thick-Shell TetrahedralShaped Nanocrystals with Emission Tunable to Near-Infrared. Journal of the American Chemical Society, Vol. 132, N. 16, pp. 5592-5593, ISSN 0002-7863.

Donegá, C. M.; Bode, M. \& Meijerink, A. (2006). Size- and Temperature-dependence of Exciton Lifetimes in CdSe Quantum Dots. Physical Review B Vol.74, N.8 , pp. 085320 (1-9), ISSN 0163-1829.

Dovichi, N. J. \& Harris, J. M. (1979). Laser Induced Thermal Lens Effect for Calorimetric Trace Analysis. Analytical Chemistry Vol. 51, N. 6, pp. 728-731, ISSN 0003-2700.

Du, W. \& Liu, S. (1993). Single Beam Self-Interaction in Langmuir-Blodgett Films. Optics Communications Vol. 98, N. 1-3, pp. 117-119, ISSN 0030-4018.

Durbin, S. D.; Arakelian, S. M. \& Shen, Y. R. (1981). Laser-induced Diffraction Rings from a Nematic-Liquid-Crystal film Optics Letters Vol. 6, N. 9, pp. 411-413, ISSN 0146-9592.

Dzhagan, V. M.; Valakh, M. Y.; Raevskaya, A. E.; Stroyuk, A. L.; Kuchmiy, S. Y.; Zahn, D. R. T. (2007). Resonant Raman Scattering Study of CdSe Nanocrystals Passivated with CdS and ZnS. Nanotechnology Vol.18, N. 28, pp. 285701(1-7), ISSN 0957-4484.

El-Kashef, H. (2002). Study of the Refractive Properties of Laser Dye Solvents: Toluene, Carbon Disulphide, Chloroform, and Benzene. Optical Materials Vol. 20, N. 2, pp. 81-86, ISSN 0925-3467.

Evident Technologies Inc. (September 2005). Nanomaterials Catalog V7.

Fang, H. L. \& Swofford, R. L. (1979). Analysis of the Thermal Lensing Effect for an Optically Thick Sample-A Revised Model. Journal of Applied Physics Vol. 50, N. 11, pp. 66096615, ISSN 0021-8979.

Ge, Z.; Kang, Y.; Taton, T. A.; Braun, P. V. \& Cahill, D. G. (2005). Thermal Transport in Aucore Polymer-shell Nanoparticles. Nano Letters Vol. 5, N. 3, pp. 531- 535, ISSN 15306984.

Goyanes, S. N.; Marconi, J. D.; Konig, P. G; Rubiolo, G. H.; Matteo, C. L. \& Marzocca, A. J. (2001). Analysis of Thermal Diffusivity in Aluminum (particle) - filled PMMA Compounds. Polymer Vol. 42, N. 12, pp. 5267-5274. ISSN 0032-3861.

Hickmann, J. M.; Gomes, A. S. L. \& Araújo, C. B. (1992). Observation of Spatial Cross-Phase Modulation Effects in a Self-Defocusing Nonlinear Medium. Physical Review Letters Vol. 68, N. 24 , pp. 3547- 3550, ISSN 0031-9007.

Jasieniak, J.; Pacifico, J.; Signorini, R.; Chiasera, A.; Ferrari, M.; Martucci, A. \& Mulvaney, P. (2007). Luminescence and Amplified Stimulated Emission in CdSe-ZnSNanocrystal-Doped TiO2 and ZrO2 Waveguides. Advanced Functional Materials Vol. 17, N. 10, pp. 1654-1662, ISSN 1616-301X.

Jose, R.; Zhanpeisov, N. U.; Fukumura, H.; Baba, Y. \& Ishikawa, M. (2006a). Structure Property Correlation of CdSe Clusters Using Experimental Results and FirstPrinciples DFT Calculations. Journal of the American Chemical Society, Vol. 128, N. 2, pp. 629-636, ISSN 0002-7863.

Jose, R.; Zhelev, Z.; Bakalova, R.; Baba, Y. \& Ishikawa, M. (2006b). White-light-emitting CdSe Quantum Dots Synthesized at Room Temperature. Applied Physics Letters V. 89, N. 1, pp. 013115(1-3), ISSN 0003-6951.

Katz, D.; Wizansky, T.; Millo, O.; Rothenberg, E.; Mokari, T. \& Banin, U. (2002). SizeDependent Tunneling and Optical Spectroscopy of CdSe Quantum Rods. Physical Review Letters Vol. 89, N. 8, pp. 86801 (1-4), ISSN. 0031-9007. 
Khitrova, G.; Gibbs, H. M.; Kawamura, Y.; Iwamura, H.; Ikegami, T.; Sipe, J. E. \& Ming, L. (1993) Spatial Solitons in a Self-focusing Semiconductor Gain Medium. Physical Review Letters Vol. 70, N. 7, pp. 920-923, ISSN 0031-9007.

Kilina, S.; Ivanov, S. \& Tretiak, S. (2009). Effect of Surface Ligands on Optical and Electronic Spectra of Semiconductor Nanoclusters, Journal of the American Chemical Society Vol. 131, N. 22, pp. 7717-7726, ISSN 0002-7863.

Kim, S.; Fisher, B.; Eisler, H.J. \& Bawendi, M. (2003). Type-II Quantum Dots: CdTe/CdSe (Core/Shell) and CdSe/ZnTe (Core/Shell) Heterostructures. Journal of the American Chemical Society Vol. 125, N. 38, pp. 11466-11467, ISSN 0002-7863.

Klimov, V. I. (2003). Nanocrystal Quantum Dots from Fundamental Photophysics to Multicolor Lasing. Los Alamos Science Vol. 28, N. 28, pp. 214-220, ISSN 0273-7116.

Klimov, V. I.; Ivanov, S. A.; Nanda, J.; Achermann, M.; Bezel, I.; McGuire, J. A. \& Piryatinski, A. (2007). Single-Exciton Optical Gain in Semiconductor Nanocrystals. Nature Vol. 447, N. 7143, pp. 441-446, ISSN 0028-0836.

Kohanzadeh, Y.; Ma, K. W. \& Whinnery, J. R. (1973). Measurement of Refractive Index Change with Temperature Using Thermal Self-Phase Modulation. Applied Optics Vol. 12, N. 7, pp. 1584-1587, ISSN 1559-128X.

Kortan, A. R.; Hull, R.; Opila, R. L.; Bawendi, M. G.; Steigerwald, M. L.; Carroll, P. J. \& Brus, L. E. (1990). Nucleation and Growth of CdSe on ZnS Quantum Crystallite Seeds, and Vice Versa, in Inverse Micelle Media. Journal of the American Chemical Society Vol. 112, N. 4, pp. 1327-1332, ISSN 0002-7863.

Lee,Y. J.; Kim, T. G. \& Sung Y. M. (2006). Lattice Distortion and Luminescence of CdSe/ZnSe Nanocrystals. Nanotechnology Vol. 17, N. 14, pp. 3539-3542, ISSN 09574484 .

Leite, R.C.C. \& Porto, S.P.S. (1966). Enhancement of Raman Cross Section in CdS due to Resonant Absorption. Physical Review Letters Vol. 17, N. 1, pp. 10-12, ISSN 00319007.

Lima, S. M.; Sampaio, J. A.; Catunda, T.; Bento, A. C.; Miranda, L. C. M. \& Baesso, M. L. (2000). Mode-mismatched Thermal Lens Spectrometry for Thermo-optical Properties Measurement in Optical Glasses: a Review, Journal of Non-Crystalline Solids Vol. 273, N. 1-3, pp. 215-227, ISSN 0022-3093.

Lippens, P. E. \& Lannoo, M. (1989). Calculation of the Band Gap for Small CdS and ZnS Crystallites. Physical Review B Vol. 39, N. 15, pp. 10935-10942, ISSN 0163-1829.

Liu, Y.; Brandon,R.; Cate, M.; Peng, X.; Stony, R \& Johnson, M. (2007). Detection of Pathogens Using Luminescent CdSe/ZnS Dendron Nanocrystals and a Porous Membrane Immunofilter. Analytical Chemistry Vol. 79, N. 22, pp. 8796-8802, ISSN 0003-2700.

Lo, S. S.; Khan, Y.; Jones, M. \& Scholes, G. D. (2009). Temperature and Solvent Dependence of CdSe/CdTe Heterostructure Nanorod Spectra. The Journal of Chemical Physics Vol. 131, N. 8, pp. 084714 (1-10), ISSN 0021-9606.

Martínez-Castañón, G. A.; Loyola-Rodríguez, J. P.; Reyes-Macías, J. F. \& Ruiz, N.N.M.F. (2010). Synthesis and Optical Properties of Functionalized CdS Nanoparticles with Different Sizes. Superficies y Vacío Vol. 23, N. 4, pp. 1-4, ISSN 1665-3521.

McBride, J. R.; Dukes, A. D.; Schreuder, M. A. \& Rosenthal, S. J. (2010). On Ultrasmall Nanocrystals. Chemical Physics Letters Vol. 498, N. 1-3, pp. 1-9, ISSN 0009-2614. 
Nguyen, K. A.; Day, P. N. \& Pachter, R. (2010). Understanding Structural and Optical Properties of Nanoscale CdSe Magic-Size Quantum Dots: Insight from Computational Prediction. The Journal of Physical Chemistry C Vol. 114, N. 39, pp. 16197-16209, ISSN 1932-7447.

Nien, Y. T.; Zaman, B.; Ouyang, J.; Chen, I. G; Hwang, C. S. \& Yu, K. (2008). Raman Scattering for the Size of CdSe and CdS Nanocrystals and Comparison with Other Techniques. Materials Letters Vol. 62, N. 30, pp. 4522-4524, ISNN 0167-577X.

Nikogosyan, D. N. (1997). Properties of Optical and Laser-Related Materials: A Handbook, Wiley, ISBN-13: 978-0-471-97384-3, Chichester, UK, pp. 469-470.

Nirmal, M.; Murray, C. B. \& Bawendi, M. G. (1994) Fluorescence-line Narrowing in CdSe Quantum Dots: Surface Localization of the Photogenerated Exciton, Physical Review $B$ Vol. 50, N. 4, pp. 2293-2300, ISSN 0163-1829.

Norris, D. J.; Efros, A. L.; Rosen, M. \& Bawendi, M. G. (1996). Size Dependence of Exciton Fine Strucutre in CdSe Quantum Dots. Physical Review B Vol. 53, N. 24, pp. 1634716354, INSS 0163-1829.

Ong, Q. K. \& Sokolov, I. (2007). Attachment of Nanoparticles to the AFM Tips for Direct Measurements of Interaction Between a Single Nanoparticle and Surfaces. Journal of Colloid and Interface Science Vol. 310, N. 2, pp. 385-390, ISSN 0021-9797.

Ono, H. \& Kawatsuki, N. (1997). Self-Phase Modulation Induced by a He-Ne Laser in HostGuest Liquid Crystals with Different Nematic-Isotropic Transition Temperatures. Japanese Journal of Applied Physics Vol. 36, N. 3B, pp. L353-L356, ISSN 0021-4922.

Ono, H. \& Saito, I. (1999). Characterization of Self-Phase Modulation in Liquid Crystals on Dye-Doped Polymer Films. Japanese Journal of Applied Physics Vol. 38, N. 10 A, pp. 5971-5976, ISSN 0021-4922.

Ouyang, J.; Zaman, M. B.; Yan, F. J.; Johnston, D.; Li, G.; Wu, X.; Leek, D.; Ratcliffe, C. I.; Ripmeester, J. A. \& Yu, K. (2008). Multiple Families of Magig-Sized CdSe Nanocrystals with Strong Bandgap Photoluminescence via Noninjection One-Pot Syntheses. The Journal of Physical Chemistry C Vol. 112, N. 36, pp. 13805-13811, ISSN 1932-7447.

Park, Y.S.; Dmytruk, A.; Dmitruk, I.; Kasuya, A.; Takeda, M.; Ohuchi, N.; Okamoto, Y.; Kaji, N.; Tokeshi, M. \& Baba, Y. (2010). Size-Selective Growth and Stabilization of Small CdSe Nanoparticles in Aqueous Solution. ACS Nano, Vol. 4, N. 1, pp. 121-128, ISSN 1936-0851.

Peng, Z. A. \& Peng, X. (2002). Nearly Monodiperse and Shape-Controlled CdSe Nanocrystals via Alternative Routes: Nucleation and Growth. Journal of the American Chemical Society Vol. 124, N. 13, pp. 3343-3353, ISSN 0002-7863.

Petrov, D. V.; Gomes, A. S. L. \& Araújo, C. B. (1994). Spatial Phase Modulation due to Thermal Nonlinearity in Semiconductor-doped Glasses. Physical Review B Vol. 50, N. 13, pp. 9092-9097, ISSN 0163-1829.

Pilla, V.; Catunda, T.; Balogh, D. T.; Faria, R. M. \& Zilio, S. C. (2002). Thermal Lensing in Poly(vinyl alcohol)/polyaniline Blends. Journal of Polymer Science. Part B: Polymer Physics Vol. 40, N. 17, pp. 1949-1956, ISSN 0887-6266.

Pilla, V.; Menezes, L. S.; Alencar, M. A. R. C. \& Araújo, C. B. (2003). Laser-Induced Conical Diffraction due to Cross-Phase Modulation in a Transparent Medium. Journal of the Optical Society of America B Vol. 20, N. 6, pp. 1269-1272, ISSN 0740-3224. 
Pilla, V.; Alves, L. P.; Munin, E. \& Pacheco, M. T. T. (2007). Radiative Quantum Efficiency of CdSe/ZnS Quantum Dots Suspended in Different Solvents. Optics Communications Vol. 280, N. 1, pp. 225-229, ISSN 0030-4018.

Pilla, V.; Alves, L. P.; Pacheco, M. T. T. \& Munin, E. (2008). Radiative Quantum Efficiency of CdSe/ZnS Core-shell Colloidal Solutions: Size-dependence. Optics Communications Vol. 281, N. 23, pp. 5925-5928, ISSN 0030-4018.

Pilla, V.; Munin, E. \& Gesualdi, M. R. R. (2009). Measurement of the Thermo-optic Coefficient in Liquids by Laser-induced Conical Diffraction and Thermal Lens Techniques. Journal of Optics A: Pure and Applied Optics Vol. 11, N. 10, pp. 105201 (17), ISSN 1464-4258.

Prasad, P. N. (2004). Nanophotonics, John Wiley \& Sons, ISBN-13: 9780471649885, New York.

Qu, L. \& Peng, X. (2002). Control of Photoluminescence Properties of CdSe Nanocrystals in Growth. Journal of the American Chemical Society, Vol. 124, N. 9, pp. 2049-2055, ISSN 0002-7863.

Rao, A.; Schoenenberger, M.; Gnecco, E.; Glatzel, T.; Meyer, E.; Brändlin, D. \& Scandella, L. (2007). Characterization of Nanoparticles using Atomic Force Microscopy. Journal of Physics: Conference Series Vol. 61, N. 1, pp. 971-976, ISSN 1742-6588.

Rathore, K. S.; Patidar D.; Janu, Y.; Saxena, N. S.; Sharma, K. \& Sharma, T. P. (2008). Structural and Optical Characterization of Chemically Synthesized ZnS Nanoparticles. Chalcogenide Letters Vol.5, N. 6, pp. 105-110, ISSN 1584-8663.

Reiss, P.; Bleuse, J. \& Pron, A. (2002) Highly Luminescent CdSe/ZnSe Core/Shell Nanocrystals of Low Size Dispersion. Nano Letters Vol. 2, N. 7, pp. 781-784, ISSN 1530-6984.

Resch-Genger, U.; Grabolle, M.; Cavaliere-Jaricot, S.; Nitschke, R.; Nann, T. (2008). Quantum Dots versus Organic Dyes as Fluorescent Labels. Nature Methods Vol. 5, N. 9, pp. 763-775, ISSN 1548-7091.

Sheldon, S. J.; Knight, L. V. \& Thorne, J. M. (1982). Laser-induced Thermal Lens Effect: a New Theoretical Model. Applied Optics Vol. 21, N. 9, pp. 1663-1669, ISSN 1559128X.

Shen, J.; Lowe, R. D. \& Snook, R. D. (1992). A Model for cw Laser Induced Modemismatched Dual-beam Thermal Lens Spectrometry. Chemical Physics Vol. 165, N. 2-3, pp. 385-396, ISSN 0301-0104.

Soloviev, V. N.; Eichhofer, A.; Fenske, D. \& Banin, U. (2000). Molecular Limit of a Bulk Semiconductor: Size Dependence of the "Band Gap" in CdSe Cluster Molecules. Journal of the American Chemical Society Vol.122, N. 11, pp. 2673-2674, ISSN 0002-7863.

Singha, A.; Satpati, B.; Satyam, P.V. \& Roy, A. (2005). Electron and Phonon Confinement and Surface Phonon Modes in CdSe-CdS Core-Shell Nanocrystals. Journal of Physics: Condensed Matter Vol. 17, N. 37, pp. 5697-5708, ISSN 0953-8984.

Snook, R. D. \& Lowe, R. D. (1995). Thermal Lens Spectrometry. A Review. Analyst Vol. 120, N. 8, pp. 2051-2068, ISSN 0003-2654.

Sounderya, N. \& Zhang, Y. (2008) Use of Core/Shell Structured Nanoparticles for Biomedical Applications. Recent Patents on Biomedical Engineering. Vol. 1, N. 1, pp. 34-42, ISSN 1874-7647.

Torruellas, W. E.; Wang, Z.; Hagan, D. J.; Vanstryland, E. W.; Stegeman, G. I.; Torner, L. \& Menyuk, C. R. (1995). Observation of Two-Dimensional Spatial Solitary Waves in a 
Quadratic Medium. Physical Review Letters Vol. 74, N. 25, pp. 5036-5039, ISSN 00319007.

Valerini, D.; Cretí, A.; Lomascolo, M.; Manna L.; Cingolani, R. \& Anni, M. (2005). Temperature Dependence of the Photoluminescence Properties of Colloidal CdSe/ZnS core/shell Quantum Dots Embedded in a Polystyrene Matrix. Physical Review B Vol. 71, N. 23, pp. 235409 (1-6), ISSN 0163-1829.

Valley, J. F.; Khitrova, G.; Gibbs, H. M.; Granthan, J. W. \& Jiajin, X. (1990). Cw Conical Emission: First Comparison and Agreement between Theory and Experiment. Physical Review Letters Vol. 64, N. 20, pp. 2362-2365, ISSN 0031-9007.

Yang, X.; Qi, S.; Zhang, C.; Chen, K.; Liang, X.; Yang, G.; Xu, T.; Han, Y. \& Tian, J. (2005). The study of self-diffraction of mercury dithizonate in polymer film Optics Communications Vol. 256, N. 4-6, pp. 414-421, ISSN 0030-4018.

Yu, K.; Hu, M. Z.; Wang, R.; Piolet, M. L.; Frotey, M.; Zaman, M. B.; Wu, X.; Leek, D. M.; Tao, Y.; Wilkinson, D. \& Li, C. (2010). Thermodynamic Equilibrium-Driven Formation of Single-Sized Nanocrystals : Reaction Media Tuning CdSe Magic-Sized versus Regular Quantum Dots, The Journal of Physical Chemistry C Vol. 114, n. 8, pp. 3329-3339, ISSN 1932-7447.

Yu, W. W.; Qu, L.; Guo, W. \& Peng, X. (2003). Experimental Determination of the Extinction Coefficient of CdTe, CdSe and CdS Nanocrystals. Chemistry of Material Vol. 15, N. 14, pp. 2854-2860, ISSN 0897-4756.

Whinnery, J.; Miller, D. \& Dabby, F. (1967). Thermal Convection and Spherical Aberration Distortion of Laser Beams in Low-Loss Liquids. IEEE Journal of Quantum Electronics Vol. 3, N. 9, pp. 382-383, ISSN 0018-9197.

Zou, S. \& Weaver, M. J. (1999). Surface-Enhanced Raman Scattering of Ultrathin Cadmium Chalcogenide Films on Gold Formed by Electrochemical Atomic-Layer Epitaxy: Thickness-Dependent Phonon Characteristics. The Journal of Physical Chemistry B Vol. 103, N. 13, pp. 2323-2326, ISSN 1932-7447. 


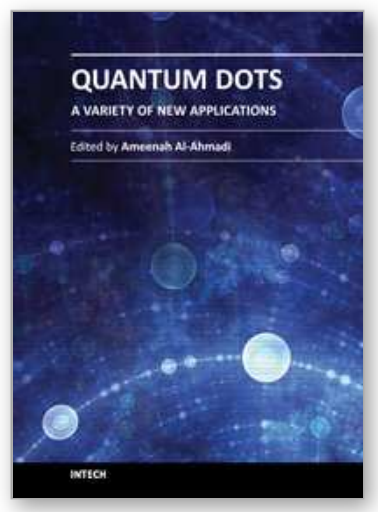

\section{Quantum Dots - A Variety of New Applications}

Edited by Dr. Ameenah Al-Ahmadi

ISBN 978-953-51-0483-4

Hard cover, 280 pages

Publisher InTech

Published online 04, April, 2012

Published in print edition April, 2012

The book "Quantum dots: A variety of a new applications" provides some collections of practical applications of quantum dots. This book is divided into four sections. In section 1 a review of the thermo-optical characterization of CdSe/ZnS core-shell nanocrystal solutions was performed. The Thermal Lens (TL) technique was used, and the thermal self-phase Modulation (TSPM) technique was adopted as the simplest alternative method. Section 2 includes five chapters where novel optical and lasing application are discussed. In section 3 four examples of quantum dot system for different applications in electronics are given. Section 4 provides three examples of using quantum dot system for biological applications. This is a collaborative book sharing and providing fundamental research such as the one conducted in Physics, Chemistry, Biology, Material Science, Medicine with a base text that could serve as a reference in research by presenting up-todate research work on the field of quantum dot systems.

\section{How to reference}

In order to correctly reference this scholarly work, feel free to copy and paste the following:

Viviane Pilla, Egberto Munin, Noelio O. Dantas, Anielle C. A. Silva and Acácio A. Andrade (2012). Photothermal Spectroscopic Characterization in CdSe/ZnS and CdSe/CdS Quantum Dots: A Review and New Applications, Quantum Dots - A Variety of New Applications, Dr. Ameenah Al-Ahmadi (Ed.), ISBN: 978-953-51-0483-4, InTech, Available from: http://www.intechopen.com/books/quantum-dots-a-variety-of-newapplications/photothermal-spectroscopic-characterization-in-cdse-zns-and-cdse-cds-quantum-dots-a-reviewand-new-a

\section{INTECH}

open science | open minds

\section{InTech Europe}

University Campus STeP Ri

Slavka Krautzeka 83/A

51000 Rijeka, Croatia

Phone: +385 (51) 770447

Fax: +385 (51) 686166

www.intechopen.com

\section{InTech China}

Unit 405, Office Block, Hotel Equatorial Shanghai

No.65, Yan An Road (West), Shanghai, 200040, China 中国上海市延安西路65号上海国际贵都大饭店办公楼405单元

Phone: +86-21-62489820

Fax: +86-21-62489821 
(C) 2012 The Author(s). Licensee IntechOpen. This is an open access article distributed under the terms of the Creative Commons Attribution 3.0 License, which permits unrestricted use, distribution, and reproduction in any medium, provided the original work is properly cited. 